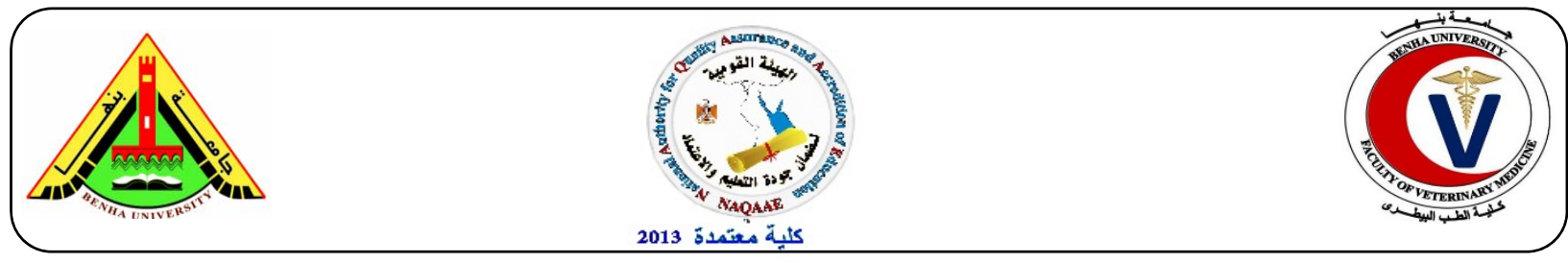

\title{
A survey on presence of new strains of infectious bronchitis virus in some chicken farms of Egyptian Delta provinces during 2014
}

\author{
Reda, R. Fathy ${ }^{1}$, El boraay, I.M ${ }^{1}$, El shorbagy, M.A ${ }^{1}$, Susan, S. El-Mahdy ${ }^{2}$ \\ ${ }^{1}$ Department of poultry diseases, Faculty of Veterinary Medicine, Benha University, Egypt. \\ ${ }^{2}$ Central Lab. for Evaluation of Vet. Biologics, Absassia, Cairo, Egypt
}

\begin{abstract}
A B S T R A C T
Seven Infectious bronchitis virus (IBV) isolates were recovered from 62 broiler and layer chicken farms collected from 4 Egyptian Delta provinces (Al Qalubia, Al Sharkia, Al Menofia and Al Gharbia) from May 2013 till July 2014 for drawing the epidemiological chart of distribution of IBV through the forementioned localities. The cardinal signs of the disease in layers were drop in egg production, with watery albumen, inferior (pale-misshape shell) eggs, while in broilers were respiratory distress, renal urate deposition and mortality. Identification of IBV was by reverse transcriptase -polymerase chain reaction (RT-PCR) of RNA extracted from trachea and kidney tissues from freshly dead birds. There were $7 / 16$ (about $43.7 \%$ ) of selected suspected farms were positive for IBV with RT-PCR. A 600bp hypervariable spike glycoprotein (S1) gene was amplified and sequenced to study genetic diversity between viruses. Sequence analysis was successfully performed with six isolates and failed with one isolate. The phylogenetic analysis revealed that four isolates related to variant Israelin strains, three of them related to (IS/1494/06 ) and other one related to( IB isolate-variant -2 S1). Other two isolates ,one of them related to classical vaccinal strain (H120) and other related to variant vaccinal strain (D274). Using two IBV isolates related to IS/1494/06 as challenging viruses one of them respiratory form and other nepherotropic form , 6 different vaccination programs of different commercial available IB vaccines. The results indicated that priming with M48 vaccine at 7 day old followed by IB Primer one week later gave the highest protection as assessed by clinical signs, weight loss, antibody titer and histopathological lesion of trachea and kidneys.
\end{abstract}

Key words: IBV, chicken, RT-PCR, vaccines

(http://www.bvmj.bu.edu.eg) conference issue

(BVMJ-28(2): 248-262, 2015)

\section{INTRODUCTION}

Infectious bronchitis (IB) is an acute and highly contagious respiratory disease of chickens. The disease is characterized by respiratory signs including gasping, coughing, sneezing, tracheal rales, and nasal discharge. In young chickens, severe respiratory distress may occur; while in layers, respiratory distress, decrease in egg production, and loss of internal and shell quality of eggs. Several strains of IBV have a strong affinity for the kidney (nephropathogenic strains) and may be associated with high mortality (Gorgyo et al., 1984). IBV is belong to group 3 coronavirus (Cavanagh, 2003). It is an enveloped, non segmented, positive sense single stranded RNA virus. IBV genome consists of about $27 \mathrm{~kb}$ and codes for three structural proteins: the spike (S) glycoprotein, the membrane (M) glycoprotein, and the nucleocapsid (N) phosphoprotein. The $\mathrm{S}$ glycoprotein is composed of two glycopolypeptides: S1 and S2 (Cavanagh, 1983). Neutralizing and serotype-specific antibodies are directed against the $\mathrm{S} 1$ glycoprotein, and the greatest divergence in the amino acid sequence is concentrated between residues 53 and 148 of S1 (Wang et al., 1997). IBV readily undergoes mutation in chickens resulting in 
the emergence of new variant serotypes and genotypes. Mutations occur frequently in hypervariable regions of the S1 subunit of the envelope spike (S) glycoprotein gene. The $\mathrm{S} 1$ protein is responsible for infection of the host cell (Cavanagh \& Davis, 1986; Koch et al., 1990) inducing virus neutralizing antibody (Cavanagh et al., 1988) and immunity (Cavanagh et al., 1997). New variant strains may differ as much as $55 \%$ in their S1 amino acid sequence compared with vaccine strains (Kusters et al ., 1987). IBV has a constant threat to the poultry industry because of the isolation of new variant serotypes of the virus even from vaccinated flocks of different immune status (Gelb, 1989; Wang and Tsai, 1996). Till now, more than 60 serotypes or IBV variants have been identified worldwide (Ignajatovic and Sapats, 2000; Yu et al., 2001), against which little or even no-cross protection existed. Because of this fact, determining and updating the exact serotypic identity of field strains prevalent in poultry farms in Egypt is very essential for selecting the effective vaccine capable to overcome the problem of IB disease in Egypt. The aim of the present study was directed to carried out surveillance study on the affected chickens flocks suffering from respiratory, urinary and egg production problem. Isolation of IBV from chicken farms in the selected governorates as El Qalubia, El Sharkia, El Menofia , and El Gharbia, Identification and molecular characterization of the isolated strains through known genetic structure, Phylogenetic analysis of the isolated strains through known differences between them and reference isolates that publicated in Gen Bank in addition to experimental trail for evaluation the efficacy of some living classical and variant IB vaccines against two local isolated strains related to variant (IS/1494/06).

\section{MATERIALS AND METHODS}

\subsection{Sampling}

Trachea and kidneys were collected aseptically from 62 commercial broiler and layer chicken flocks showing respiratory disorders, anorexia, loss of bodyweight in broiler, while in layer flocks showing problems in egg production started from May 2013 till July 2014. As shown in table (1)

Tabel (1): showing number of farms were suspected to infected with IB

\begin{tabular}{ccccc}
\hline Governorate & Al-Qalubia & Al -Sharkia & Al -Menofia & Al-Gharbia \\
\hline Number & 49 & 7 & 5 & 1 \\
\hline
\end{tabular}

\subsection{Virus isolation using Embryonated SPF eggs.}

The samples were homogenized to give approximately $10 \%(\mathrm{w} / \mathrm{v})$ suspension in PBS pH 7.2 containing 100IU/ml penicillin, $100 \mu \mathrm{g} / \mathrm{ml}$ streptomycin, and 30 IU amphotericin $\mathrm{B} / \mathrm{ml}$. The homogenized samples were centrifuged at $1000 \mathrm{~g}$ for $15 \mathrm{~min}$ at $4^{\circ} \mathrm{C}$ and then filtered through a $0.45 \mu \mathrm{m}$ filter membrane The supernatant was inoculated at $0.2 \mathrm{ml}$ via the allantoic cavity of five 9-11 day-old SPF eggs( KoomOshiem, Fayoum,AgricultureResearchCenter -
Ministry of griculture).Allantoic fluids were harvested at $96 \mathrm{~h}$ post inoculation. Three successive blind serial passages were performed. The allantoic fluids were harvested and stored at $-70 \mathrm{C}$ with examination of embryo for curling and dwarfism (Momayez et al., 2002).

\subsection{IBV detection by RT-PCR}

RNA was extracted from the supernatants of $10 \% \mathrm{w} / \mathrm{v}$ sample suspensions and allantoic fluid collected 4 day post inoculation. The extraction of viral RNA was performed using a (viral RNA kit 
Axygen Biosciences ) according to the manufacturer s instructions . Amplification of the specific target genome of ( S1 gene) was conducted using the forward primer 5ACT ACT ACC AAA GTG CCT-3 and reverse primer 5- ACA TCT TGT GCA GTA CCA TTA ACA-3 .for final product $(600 \mathrm{bp})$ with the following cycling conditions: initial denaturation at $95^{\circ} \mathrm{C}$ for $2 \mathrm{~min} ; 35$ cycles of $95^{\circ} \mathrm{C}$ for $20 \mathrm{sec} ; 55^{\circ} \mathrm{C}$ for $30 \mathrm{sec} ; 72^{\circ} \mathrm{C}$ for $1 \mathrm{~min}$, followed by a final extension of $72^{\circ} \mathrm{C}$ for $5 \mathrm{~min}$.

\subsection{Genetic characterization of hypervariable region of S1 gene}

For identification of positive IBV isolates ,HVR of S1 gene were amplified using conventional PCR by Qiagen one step RTPCR kit (Qiagen, GmbH and Hilden, Germany) using forward and reverse primers as previously mentioned. The amplicons were purified using the_Promega PCR Purification Kit. The sequence reactions performed using genetic analyzer Applied Biosystems 3130(ABI, USA) by Big dye Terminator V3.1 cycle sequencing kit. The sequence analysis of the spike S1 gene of the isolated IBV strains, sequences used for comparison in this study were from GenBank and were available from the National Center for Biotechnologys sequence Information (NCBI).Sequence identities were calculated using DNAstar software and the phylogenetic tree of the nucleaotide sequence were constructed using Mega 5. The sequences from the GenBank used in this study include H120 (Acc no.JN600610), Connecticut (Acc no.AF094818), Ma5 (Acc no.AY561713), M41(Acc no.HF674411) , CR88 (Acc no.JN592567), 4/91 (Acc no.AF093794), D274 (Acc no.X15832), QXIBV (Acc no.GQ253481), IBV-SI-1494 (Acc no. HM131453) and IS-885 S1 (Acc no.AY279533), IS/1366-sp1 (Acc no.EU350550), Egypt -F-03 (Acc no.DQ987085).

\subsection{Challenge experiment with local field isolates}

\subsubsection{Viruses of IB :}

\subsubsection{Living infectious bronchitis vaccine}

Six IB commercial live attenuated vaccines were used: three variant IB vaccines: Nobilis IB 4/91 Batch No. (A172C1J01) : Gallivac IB88 (CR88121) Batch No. (L411424) and polyvac IB primer (D274): Batch No. (1307061D3). And another three classical IB Vaccines:Avipro IB M48 Batch No.(2414P) : H120 IZO Batch No.( 06261) and Ma5 Intervet with Batch No. (A176A1A1JOL).

\subsubsection{Challenge IB virus}

The viruses used in the challenge were two local field isolates of variant IBV $(20,22)$ which was related to variant (IS/1494/06) with different tropism respiratory form and nephrotropic form, respectively . They were in form of infectious allantoic fluid at the level of third passage, they were isolated from field cases confirmed by RT-PCR and characterized by sequencing as variant IBV strains. They were titrated in SPF embryonated eggs as described by (Villegas and purchase, 1990) with titer $\left(10 / 0.4 \mathrm{ELD}^{50 /}\right.$ bird and its calculation according to the method of (Reed and muench, 1938).

\subsubsection{Experimental host:}

One day old commercial chicks were obtained from Cairo poultry company (CPC) and taken serum samples were collected and checked by (Biocheck ELISA) to assure freedom of specific IBV antibodies. They were floor reared under hygienic condition in previously cleaned and disinfected isolated experimental rooms, Chicks were provided with commercial broiler ration, water and feed were provided adlibitum. They were used for pathogenicity test and evaluation of different vaccination programs.

\subsubsection{Enzyme -linked Immunosorbent Assay (ELISA) kit}

ELISA Kit was obtained from Biocheck poultry immune assays. Infectious 
Bronchitis Virus antibody test kit (CK119) : Serial No. F55419 product code: 5030.

\subsubsection{Scoring index for clinical and} lesion were recorded for15days post challenge according to Avellaneda et al., (1994); Wang and Huang, (2000).

\subsubsection{Reagents for histopathology} according to (Bancroft and Steven,1977) it was carried for recording changes in trachea and kidney.

\subsubsection{Statistical analysis:}

For presentation of results, the means and standard errors of the mean (SEM) were calculated. Analysis of variance (ANOVA) was performed using the Statistical Analysis System soft ware SPSS, (2004), results were considered statistically significant when $(\mathrm{P}<0.05)$.

\subsubsection{Experimental Design:}

Four hundred and twenty chicks one day old were divided into eight groups. The first six groups (1-6) consist of 60 chicks. Group 7 (control positive group) consists of 40 chicks and group 8 (control negative group) consist of 20 chicks. At 7 day old, the first six groups vaccinated through intranasal route with recommended dose of different examined commercial vaccine table (2). At 19 day of age blood sample collected from 5 chicks from 6 group and also control group all groups. Serum samples separated for measure antibody titer using ELISA, weight of 5 chicks was recorded and also taken trachea and kidneys for recorded changes before challenge. At 21 day of age each group was divided into 2 sub group (A-B ) each sub group contain 30 birds make challenge with isolate (20) for sub group A in group from( 1-7). Also make challenge with isolate( 22) for sub group B in group from (1-7) at dose of $4.0 \log 10$ ELD50 Per 0.1 $\mathrm{ml}$ administered through intranasal route and keep group (8) free from vaccine and also challenge with virus as control negative for experiment. Five days post challenge serum sample were monitored for antibody titer at 26, 31 and 36 days of age. Difference in weight and also changes that observed in the preserved trachea and kidneys in formal saline after challenge were recorded . Following challenge, all birds were observed daily for clinical signs attributable to IB infection.

Table (2): Vaccination program used in day old chick at 7 days and of 14 days.

\begin{tabular}{cll}
\hline Group & \multicolumn{2}{c}{ Type of vaccine } \\
\hline G1 & $\begin{array}{l}1^{\text {st }} \text { vaccination (At 7 day old ) } \\
\text { G2 }\end{array}$ & $\begin{array}{l}2^{\text {nd }} \text { vaccination (At 14 day old) } \\
\text { MA5 Classical }\end{array}$ \\
G3 & $\begin{array}{l}\text { CR 88 Variant } \\
\text { IB Primer Variant }\end{array}$ & H120 Classical \\
G4 & MA5 Classical & M48 Classical \\
G5 & H120 Classical & 4/91 Variant \\
G6 & M48 Classical & CR 88 Variant \\
G7 & & IB Primer Variant \\
G8 & & Control positive \\
\hline
\end{tabular}




\section{RESULTS}

\subsection{Results of infectious bronchitis virus detection in field samples}

There were 16 samples selected from suspected 62 farms for detection of IBV in the collected governorates, out of 16 samples only 7 samples were positive $7 / 16($ about $43.7 \%$ ) using RT-PCR . The positive flocks were recovered only from ALQalubia province four flocks $(8.1 \%)$ and AL-Sharkia province three flocks $(42.8 \%)$ as shown in table (3).

Table (3): Prevalence of identified IBV isolates recovered from examined organs collected from freshly dead chickens from different provines

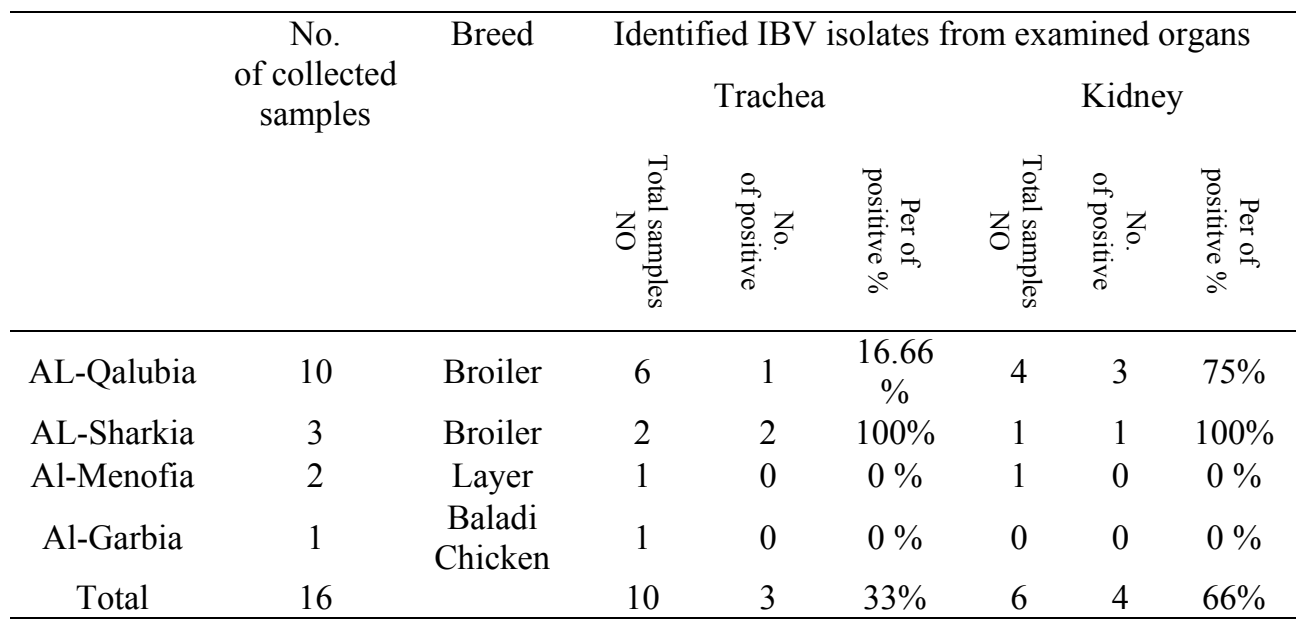

\subsection{Virus isolation}

There were 7 positive isolates were identified after egg inoculation after 3 blind passages. The inoculated embryos showed curling and dwarfing with subcutaneous hemorrhage as shown in Fig .1.

\subsection{Results of genetic analysis}

\subsubsection{Results of conventional PCR}

The allantoic fluids were collected and tested for confirmation of IBV by RT-PCR and they were positive as indicated in Fig .2. , where the 16 selected samples present in the agarose gel electrophoresis, only positive samples showed specific band at 600 bp of S1 gene.

\subsubsection{Results of Nucleotides sequence analysis}

Sequence analysis of $600 \mathrm{bp}$ of HVR of S1 gene for measuring identity and diversity between the six isolated strains and also between them and reference strains in the
GenBank. The analysis was applied with specific DNA star software for alignment, measuring of identity $\%$ among the sequence of the HVR of S1 gene of the selected isolates. As shown in table (6).

\subsubsection{Phylogenetic analysis}

The phylogenetic analysis of the 6 selected isolates were constructed (Fig 3) and revealed that our results can be divided into 3 groups as following :Group (A ) related to Variant IB vaccine, Isolate code (62) showed relatedness to (IBV D247) with maximum nucleotide identity of $88.3 \%$. Group (B ) related to Field isolate of variant IBV as following :Isolates codes (17), (20) and (22) showed high similarity to(IS/1494/06 )with maximum nucleotide identity of (98.4\%), (98.8\%) and (98.0\%) respectively .Isolate code (16) showed related to(IB isolate-variant -2 S1)with maximum nucleotide identity of $89.6 \%$. Group (C) related to Classical IB vaccine 
Table (4) The Identity and diversity of IBV based on nucleotide analysis.

\begin{tabular}{|c|c|c|c|c|c|c|c|c|c|c|c|c|c|c|c|c|c|c|c|c|c|c|}
\hline \multicolumn{23}{|c|}{ Percentldentity } \\
\hline & 1 & 2 & 3 & 4 & 5 & 6 & 7 & 8 & 9 & 10 & 11 & 12 & 13 & 14 & 15 & 16 & 17 & 18 & 19 & 20 & & \\
\hline 1 & & ${ }^{4}$ & 75.6 & 74.97 & 74.3 & 76.5 & 75.7 & 72.9 & 75.9 & 73.97 & 70.3 & 2.9 & 3.5 & 2.1 & IL.T & TL.J & & 71.5 & 76.1 & 75.7 & 1 & QXXV1.seq \\
\hline $2:$ & 29.9 & & 809 & 88.27 & 77.8 & 83.7 & 83.1 & 78.0 & 83.3 & 86.87 & 3.97 & 8.0 & 4.5 & 1.4 & 117.8 & 17.0 & 76.0 & 78.0 & 83.5 & 83.1 & 2 & 4.91.seq \\
\hline $3:$ & 29.7 & 22.2 & & 73.67 & 76.1 & 33.4 & 92.6 & 76.7 & 92.8 & 72.67 & 1.4 & 6.7 & 6.2 & 6.9 & 76.9 & 76.5 & 74.4 & 76.1 & 92.8 & 92.8 & 3 & Connecticut.seq \\
\hline 4 & 30.9 & 13.0 & & & 76.0 & 75.7 & 74.8 & 77.4 & 75.0 & 95.77 & 2.37 & 7.4 & 6.5 & 77.2 & 1.6 & 71.0 & 76.0 & 74.5 & 75.1 & 74.8 & 4 & CR88121.seq \\
\hline 5 & 31.7 & 26.6 & 29.3 & 29.3 & & 77.9 & 76.7 & 85.4 & 76.9 & 75.07 & 73.5 & 5.4 & 9.3 & 55.0 & 85.0 & 8.2 & 88.3 & 81.4 & 77.1 & 76.7 & 5 & D274.seq \\
\hline $6:$ & 28.5 & 18.5 & 6.9 & 29.82 & 26.4 & & 97.6 & 77.9 & 978 & 75.17 & 2.87 & 7.9 & 8.9 & 78.1 & $\pi .4$ & 71.5 & 75.3 & 77.3 & 98.0 & 98.0 & 6 & Egypt.-03.seq \\
\hline $7:$ & 29.6 & 19.2 & 7.8 & 31.32 & 28.2 & 2.4 & 7 & 77.1 & 99.8 & 74.27 & 1.87 & 7.1 & 9.5 & 77.3 & | & 76.7 & 74.2 & 76.9 & 99.6 & 99.2 & 7 & H 120.seq \\
\hline 8 & 33.8 & 26.2 & 28.2 & 27.11 & 16.5 & 26.3 & 27.4 & & 76.9 & 76.27 & 6.25 & 9.8 & 6.1 & 88.4 & 98.8 & 98.0 & 86.9 & 89.6 & 77.1 & 76.7 & 8 & ib- isolate- variant-2.51.seq \\
\hline 9 & 29.3 & 19.0 & 7.6 & 30.92 & 27.9 & 2.2 & 0.2 & 27.7 & & 74.47 & 2.07 & 6.9 & 9.3 & 77.1 & 76.9 & 76.5 & 74.4 & 77.1 & 99.8 & 99.4 & 9 & 1s.23691.seq \\
\hline 10 & 32.5 & 14.7 & 34.7 & 4.43 & 30.9 & 30.6 & 32.2 & 28.8 & 31.8 & 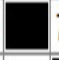 & 1.97 & 6.2 & 15.7 & 75.6 & 76.0 & 76.0 & 74.9 & 73.7 & 74.6 & 74.2 & 10 & $15 \cdot 1366 . \mathrm{seq}$ \\
\hline 11 & 37.8 & 32.2 & 36.2 & 34.83 & 33.2 & 34.0 & 35.6 & 29.0 & 35.2 & 35.5 & & 6.2 & b. & 75.8 & 75.8 & 75.2 & 75.0 & 73.7 & 72.2 & 71.8 & 11 & 19.885 \$11.seq \\
\hline 12 & 33.8 & 26.2 & 28.3 & 27.11 & 16.5 & 26.3 & 27.5 & 0.2 & 27.8 & 28.9 & 99.0 & & & 4 & 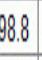 & 98.0 & 86.9 & 89.6 & 77.1 & 76.7 & 12 & 18-1494-06.seq \\
\hline 13 & 32.8 & 17.4 & 15.3 & 28.42 & 24.5 & 12.0 & 11.3 & 15.5 & 11.5 & 29.6 & 29.8 & 5.5 & & & 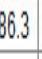 & (2). & 78.3 & 86.18 & 89.1 & 88.7 & 13 & Isolate $2 . s e q$ \\
\hline 14 & 34.1 & 27.1 & 27.9 & 27.31 & 16.9 & 26.0 & 27.1 & 1.6 & 27.4 & 29.7 & 29.5 & 1.6 & 5.7 & & 0 & 0,0 & 0.1 .1 & 89.3 & 77.3 & 76.9 & 14 & Isolate 17 .seq \\
\hline 15 & 34.1 & 26.5 & 27.9 & 26.81 & 16.9 & 26.3 & 27.4 & 1.2 & 27.7 & 29.1 & 996 & 1.2 & 5.2 & 0.4 & & & 0.1 .1 & 89.6 & 77.1 & 76.7 & 15 & Isolate 20 .seq \\
\hline 16 : & 34.7 & 26.5 & 28.5 & 26.71 & 18.0 & 66.8 & 28.0 & 20 & 28.3 & 29.1 & 30.5 & 20 & 6.5 & 1.4 & 1.0 & & 86.3 & $89.3{ }^{\circ}$ & 76.7 & 76.3 & 16 & Isolate 22.seq \\
\hline 17 & 32.3 & 29.2 & 31.6 & 29.41 & 128. & 30.2 & 32.0 & 14.5 & 31.7 & 31.2 & 30.7 & 4.5 & & 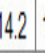 & 14.3 & 15.2 & & 83.4 & 74.6 & 74.2 & 17 & Isolate 62.seq \\
\hline 18 & 36.1 & 26.1 & 28.9 & 31.52 & 21.5 & 27.0 & 27.6 & 11.2 & 27.3 & 32.7 & 32.7 & 1.2 & & 11. & 1.2 & 1.6 & 18.8 & & $=$ & 76.5 & 18 & Isoldte 16.seq \\
\hline 19 & 29.0 & 18.7 & 7.6 & 30.72 & 27.6 & 2.0 & 0.4 & 27.5 & 0.2 & 31.5 & 34.92 & 7. & 118 & 27. & 27.4 & 28.0 & 31.4 & 27.6 & & 99. & 19 & III1.seq \\
\hline 20 & 29.6 & 19.2 & 7.6 & 31.32 & 28.2 & 2.0 & 0.8 & 28.0 & 0.6 & 32.2 & 55.6 ? & 8.1 & 2.2 & 27.7 & 28.0 & 28.6 & 32.0 & 28.2 & 0.4 & & 20 & N165.seq \\
\hline & 1 & 2 & 3 & 4 & 5 & 6 & 7 & 8 & 9 & 10 & 11 & 12 & 13 & 14 & 15 & 10 & 17 & 18 & 19 & 20 & & \\
\hline
\end{tabular}

,Isolated code (2) showed related to (IB H120) with maximum nucleotide identity of $89.5 \%$. Sequence analysis was successfully performed with six isolates and failed with one isolate. As shown in Table 5 .

Table (5): IBV isolates identification.

\begin{tabular}{cccccc}
\hline No & Governorate & $\begin{array}{c}\text { Type } \\
\text { Of production }\end{array}$ & $\begin{array}{c}\text { Age } \\
\text { (day) }\end{array}$ & $\begin{array}{c}\text { Vaccination } \\
\text { program }\end{array}$ & $\begin{array}{c}\text { Acession } \\
\text { number }\end{array}$ \\
\hline 1 & AL-Sharkia & Broiler & 28 & H120+D274 & KP279995 \\
2 & Al-Qalubia & Broiler & 22 & H120 at 1day & KP279996 \\
3 & AL-Sharkia & Broiler & 18 & H120+D274 & KP279997 \\
4 & Al-Qalubia & Broiler & 25 & Un known & KP279998 \\
5 & AL-Qalubia & Broiler & 32 & H120+D274 & KP279999 \\
6 & AL-Sharkia & Layer & 190 & H120 at 1 day & KP280000 \\
\hline
\end{tabular}

\subsection{Parameters for challenge experiment:}

\subsubsection{Clinical signs rate}

All chickens were monitored daily for clinical signs of IBV infection such as coughing, head shaking, lethargy and conjunctivitis the clinical signs were recorded according to scoring index as in table (6) 
Table (6): Clinical signs score system of infected chicks:

\begin{tabular}{lc}
\hline Clinical signs & score \\
\hline No clinical signs & 0 \\
Lacrimation, slight head shaking and watery faces & 1 \\
Lacrimation ,presence of nasal exudates, depression watery faces & 2 \\
Strong (lacrimation, presence of nasal exudates, depression ) and severe watery faces & 3
\end{tabular}

Scoring index according to Avellenda et al., (1994) and Wang and Huang (2000)

Table (7): Recording clinical signs rate after challenge with isolated code(22) in different vaccinated groups

\begin{tabular}{cccccccccccccc}
\hline Group No & \multicolumn{10}{c}{ Days post challenge and number of dead birds } & Total NO & $\begin{array}{c}\text { Total } \\
\%\end{array}$ & $\begin{array}{c}\text { Protection } \\
\%\end{array}$ \\
& 1 & 2 & 3 & 4 & 5 & 6 & 7 & 8 & 9 & $10-15$ & & & \\
\hline 1 & - & - & 1 & - & - & 1 & - & 1 & - & - & $3 / 30$ & 10 & 90 \\
2 & - & - & 1 & - & 1 & 1 & - & 1 & - & - & $4 / 30$ & 13.4 & 86.6 \\
3 & - & - & - & 1 & - & - & 1 & - & - & - & $2 / 30$ & 7 & 93 \\
4 & - & - & 1 & - & 1 & - & 1 & - & 1 & - & $4 / 30$ & 13.4 & 86.6 \\
5 & - & - & - & 1 & - & 1 & 1 & 1 & 1 & - & $5 / 30$ & 16.7 & 83.3 \\
6 & - & - & - & - & - & - & - & - & - & - & $0 / 30$ & 0 & 100 \\
\hline
\end{tabular}

N.B: Birds in groups (1.3.4) have clinical signs score (1), however in group $(2,5)$ have clinical signs score (2)

Table (8): Recording clinical signs rate after challenge with isolated code (20) in different vaccinated groups:

\begin{tabular}{cccccccccccccc}
\hline Group No & \multicolumn{10}{c}{ Days post challenge and number of dead birds } & Total NO & $\begin{array}{c}\text { Total } \\
\%\end{array}$ & $\begin{array}{c}\text { Protection } \\
\%\end{array}$ \\
& 1 & 2 & 3 & 4 & 5 & 6 & 7 & 8 & 9 & $10-15$ & & & \\
\hline 1 & - & - & 1 & - & - & - & - & 1 & - & - & $2 / 30$ & 6.6 & 93.4 \\
2 & - & - & - & 1 & 1 & 1 & - & 1 & 1 & - & $5 / 30$ & 16.7 & 83.3 \\
3 & - & - & - & - & - & 1 & - & - & - & - & $1 / 30$ & 3.4 & 96.6 \\
4 & - & - & 1 & - & 1 & - & - & - & 1 & - & $3 / 30$ & 10 & 90 \\
5 & - & - & 1 & 1 & 1 & - & - & - & 1 & - & $4 / 30$ & 13.4 & 86.6 \\
6 & - & - & - & - & - & - & - & - & - & - & $0 / 30$ & 0 & 100 \\
\hline
\end{tabular}

Table (9): Recording clinical signs after challenge in non vaccinated group (group 7)

\begin{tabular}{|c|c|c|c|c|c|c|c|c|c|c|c|c|c|}
\hline $\begin{array}{l}\text { Days post challenge and } \\
\text { number of dead birds }\end{array}$ & 1 & 2 & 3 & 4 & 5 & 6 & 7 & 8 & 9 & $10-15$ & $\begin{array}{l}\text { Total } \\
\text { NO }\end{array}$ & $\begin{array}{c}\text { Total } \\
\%\end{array}$ & $\begin{array}{c}\text { Protection } \\
\% \\
\end{array}$ \\
\hline Isolate code (20) & - & 1 & 6 & 5 & 3 & 3 & 2 & - & - & - & $20 / 20$ & 100 & 0 \\
\hline Isolate code (22) & - & - & 9 & 5 & 4 & - & - & - & - & - & $18 / 20$ & 90 & 10 \\
\hline
\end{tabular}

N.B: Clinical signs score system, the two groups were (3).

\subsubsection{Effect of IBV on body weight}

The body weight affected in all groups in compare with control (-ve) group .The first weight at19 day old before challenge showed no significant difference between birds in groups $(1,3,4$ and 6$)$ with control unvaccinated group $(p>0.05)$, birds in groups $(2,5)$ have severe effect after challenge at 26 day and body weight decrease than $1^{\text {st }}$ weight. At the end of experiment the body weight affected in group $(5,2,4,1,3,6)$ in compare with 
control group (8) respectively with significant difference $(p<0.05)$

\subsubsection{Monitoring Antibody response before and after challenge for both two isolates.}

The titer ranged between 5934.2 in group (6) and 3508.8 in group (5) while after 5 days post challenge ( 26 day old), the antibody titer affected with significant lower $(\mathrm{p}<0.05)$ due to neutralization between antibodies that produce due to vaccination and infected challenge viruses .
Birds in all groups had high protected antibody titer at 31 day old (10 day Post challenge), this elevation of antibody titer occurred due to stimulation of cellular immunity mainly macrophage and lymphocytes as defense mechanism of bird in the presence of foreign challenge virus . That elevation of titer still to 36 day old. Birds in group (6) (IB48+ primer) and group (3) (IB primer+IB48) had a high antibody level than other groups when comparison with unvaccinated negative control (156). Table (10) \& (11).

Table (10): Antibody response to different IB commercial vaccine challenge with Isolate code (22) Mean \pm Std. Error

\begin{tabular}{cccccc}
\hline Group & AT 1 day & 19 days & 26 days & 31 days & 36 days \\
& & & & & \\
\hline 1 & $2.61 \pm 0.00061$ & $3.68^{\mathrm{c}} \pm 0.00005$ & $3.23^{\mathrm{e}} \pm 0.00015$ & $3.34^{\mathrm{d}} \pm 0.00011$ & $3.43^{\mathrm{f}} \pm 0.00009$ \\
2 & $2.61 \pm 0.00061$ & $3.58^{\mathrm{e}} \pm 0.00007$ & $3.17^{\mathrm{f}} \pm 0.00017$ & $3.43^{\mathrm{b}} \pm 0.00009$ & $3.59^{\mathrm{c}} \pm 0.00006$ \\
3 & $2.61 \pm 0.00061$ & $3.76^{\mathrm{b}} \pm 0.00004$ & $3.51^{\mathrm{b}} \pm 0.00008$ & $3.39^{\mathrm{c}} \pm 0.00010$ & $3.62^{\mathrm{b}} \pm 0.00006$ \\
4 & $2.61 \pm 0.00061$ & $3.67^{\mathrm{d}} \pm 0.00005$ & $3.35^{\mathrm{c}} \pm 0.00011$ & $3.32^{\mathrm{a}} \pm 0.00012$ & $3.50^{\mathrm{d}} \pm 0.00008$ \\
5 & $2.61 \pm 0.00061$ & $3.55^{\mathrm{f}} \pm 0.00007$ & $3.32^{\mathrm{d}} \pm 0.00012$ & $3.43^{\mathrm{b}} \pm 0.00009$ & $3.49^{\mathrm{e}} \pm 0.00008$ \\
6 & $2.61 \pm 0.00061$ & $3.77^{\mathrm{a}} \pm 0.00004$ & $3.62^{\mathrm{a}} \pm 0.00006$ & $3.67^{\mathrm{a}} \pm 0.00005$ & $3.83^{\mathrm{a}} \pm 0.00004$ \\
\hline
\end{tabular}

Means of different litters are significantly different $(p<0.05)$. Value is $\log (10)$

Table (11): Antibody response to different IB commercial vaccine challenge with Isolate code (20)

\begin{tabular}{|c|c|c|c|c|c|}
\hline group & At 1 day & 19 days & 26 days & 31 days & 36 days \\
\hline 1 & $2.61^{\mathrm{a}} \pm 0.00061$ & $3.68^{c_{ \pm}} \quad 0.00005$ & $3.13^{\mathrm{f}} \pm 0.00019$ & $3.33^{\mathbf{f}_{1}} \pm 0.00012$ & $3.33^{\mathfrak{f}_{1}} \pm 0.00012$ \\
\hline 2 & $2.61^{\mathrm{a}} \pm 0.00061$ & $3.58^{\mathrm{e}} \pm 0.00007$ & $3.29^{\mathrm{e}} \pm 0.00013$ & $3.33^{\mathrm{e}} \pm 0.00012$ & $3.34^{\mathrm{e}} \pm 0.00012$ \\
\hline 3 & $2.61^{\mathrm{a}} \pm 0.00061$ & \pm 0.00004 & $3.56^{\mathbf{b}} \pm 0.00007$ & $3.50^{\mathbf{b}} \pm 0.00008$ & $3.62^{b} \pm 0.00006$ \\
\hline 4 & $2.61^{\mathrm{a}} \pm 0.00061$ & $3.67^{\mathrm{d}} \pm 0.00005$ & $3.31^{\mathbf{c}} \pm 0.00012$ & $3.47^{\mathfrak{c}} \pm 0.00008$ & $3.50^{\mathrm{d}} \pm 0.00008$ \\
\hline 5 & $2.61^{\mathrm{a}} \pm 0.00061$ & $3.55^{\mathrm{f}_{1}} \pm 0.00007$ & $3.30^{\mathrm{d}} \pm 0.00012$ & $3.40^{\mathrm{d}} \pm 0.0001$ & $3.59^{\mathbf{c}} \pm 0.00006$ \\
\hline 6 & $2.61^{a_{ \pm}} \quad 0.00061$ & $3.77^{\mathrm{a}} \pm 0.00004$ & \pm 0.00006 & $3.50^{\mathrm{a}} \pm 0.00008$ & $3.65^{\mathrm{a}} \pm 0.00006$ \\
\hline
\end{tabular}

Means of different litters are significantly different $(p<0.05)$. Value is $\log (10)$

\subsubsection{Virus detection at 36 days old (10-15 day post challenge)}

The challenge virus (code 20, 22) was detected in the trachea and kidney of each dead birds of all control (+ve) groups. The detection rate of the virus in kidney was lower than in the trachea.

The detection rate of the virus in the vaccinated groups was lower than that of the positive control group (group 7) but it was not significantly different $(p>0.05)$

\subsubsection{Histopathological findings:}

Microscopic kidney lesions; principally, kidney lesions of IBV-infected chicks were of an interstitial nephritis. The virus caused degenerative changes in the renal tubules., focal area of necrosis in the renal medulla, severe congestion of the renal blood vessels with mild inter tubular hemorrhage. Microscopic tracheal lesions: The common findings in trachea of IBVs were presence 
of eosinophilic debris in the lumen mixed with desquamated epithelial cells and mononuclear cellular aggregation. The mucosa revealed variable degrees of desquamation of the tracheal epithelium mixed with leukocytic infiltration.
Sometimes, presence of vacuoles in the tunica muscularis of the trachea. The lamina propria revealed mild congested blood vessels associated with hemorrhages, and infiltration with inflammatory cells. As shown in Fig (6) \& (7).
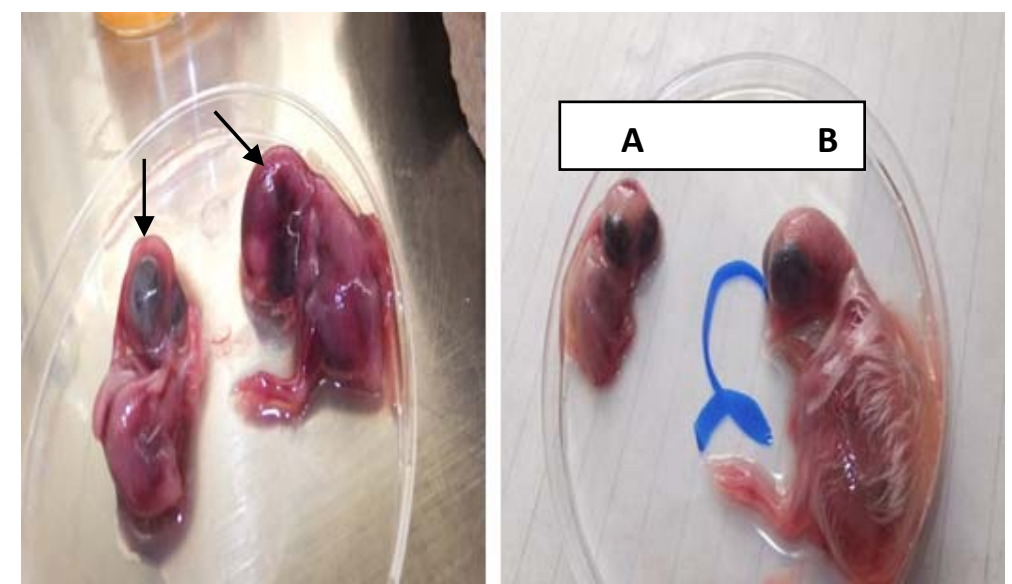

Figure (1) A: Curling, dwarfing \&subcutaneous hemorrhage. B:Normal embryo.
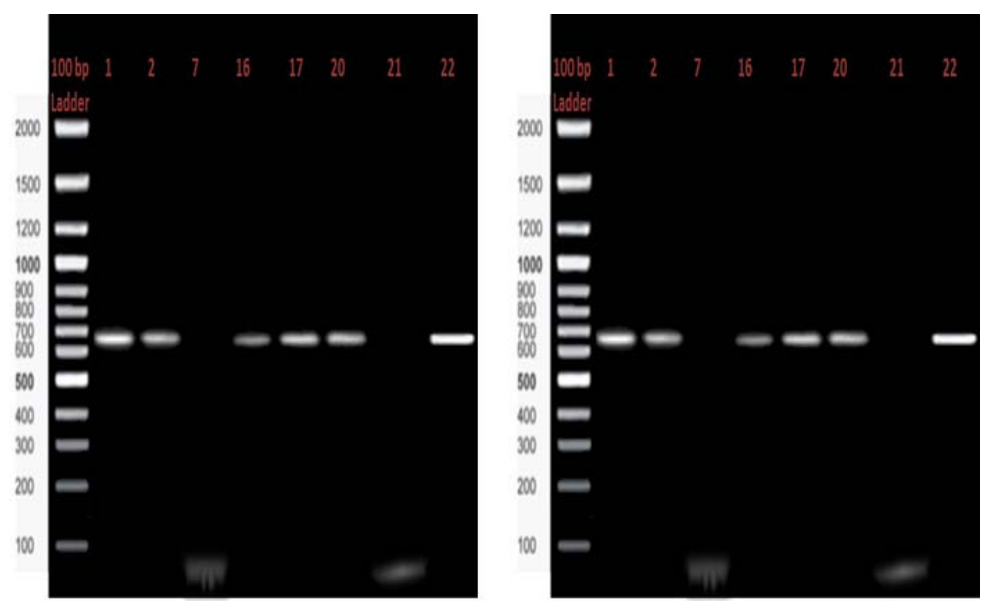

Figure (2): Agar gel electrophoresis of sixteen IB isolates. 1,2,7,16,17, 20,21,22,23,25, 27,42, 50,62, 66,65: Codes of IB isolates.

\section{DISCUSSION}

The prevalence of IBV infection via isolation in ECE and RT-PCR indicated that, Qalubia province had four positive samples (40\%) out of ten examined samples aging from 10-38 days from 49 broiler flocks, Sharkia province had three positive samples $(100 \%)$ from all three examined samples aging from 23-35 days from 7 broiler flocks, from Menofia province had negative results of two examined samples aging between 142-335 days from 5 layer flocks, Also at Gharbia province had negative result from examined baladi chicken flock aging 27 days. These results agreed with Amin and Mostageer (1977) recorded IBV from an outbreak infected broilers aged 20 - 30 days old in Qalubia province characterized by respiratory and renal symptoms in which morbidity was $80 \%$. The isolated virus induced in $\mathrm{CE}$ significant dwarfism, curling with ureates deposited in kidney, also Abdel-Moneim et al., (2002) who isolated a new strain of infectious bronchitis virus from 38 day old 
broiler chickens and the strain was identified using electron microscopy (EM),

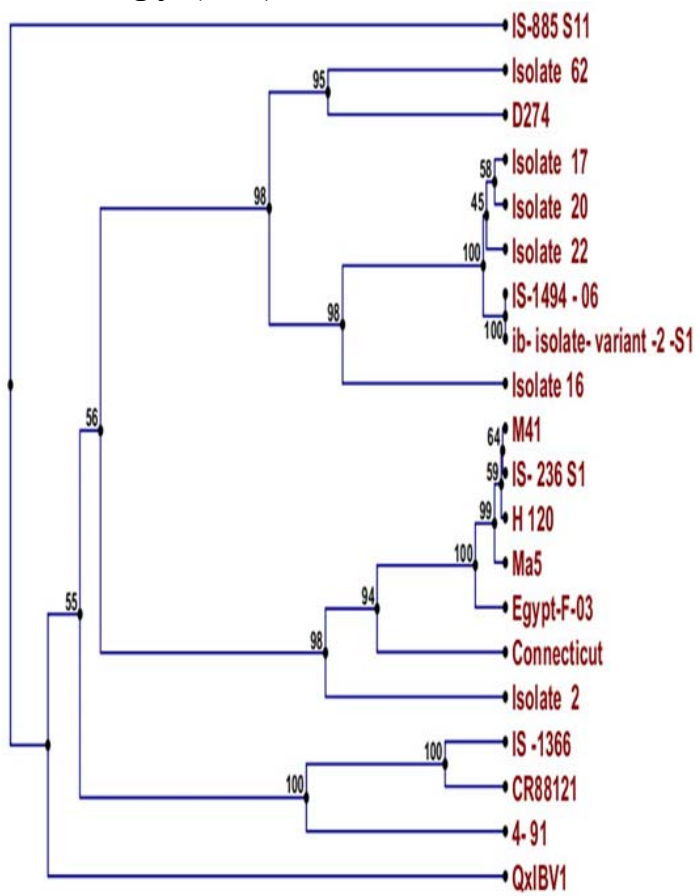

Figure (3): Phylogenetic tree of Spike S1 gene of 6 isolated viruses.
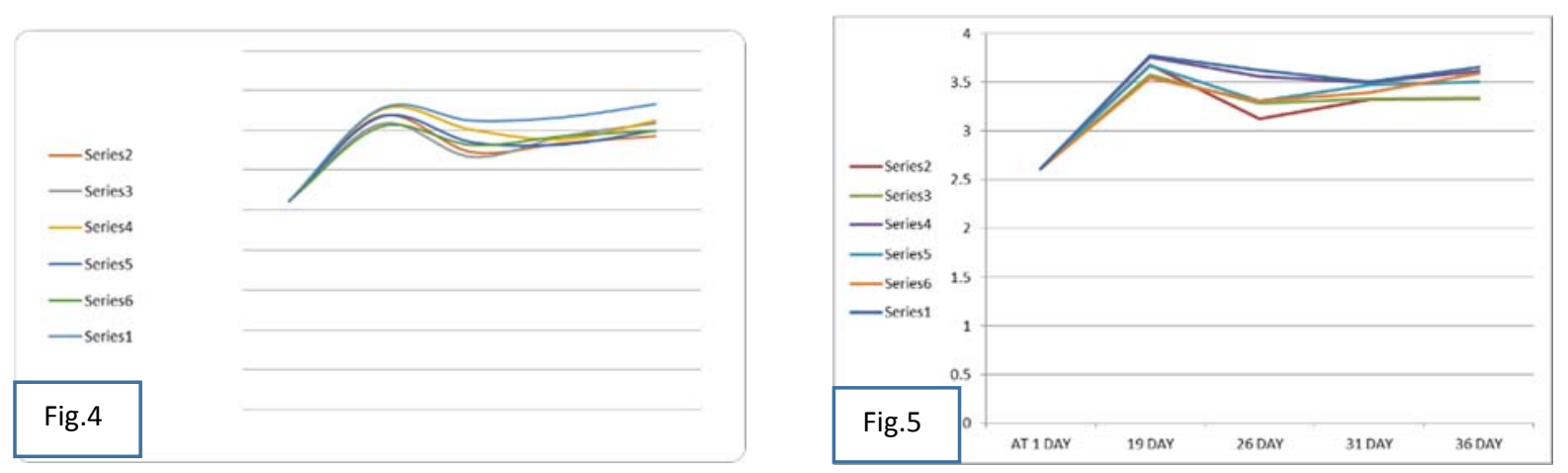

Fig (4) showing that log of antibody titer in the 6 groups, group (6) of high value in compare with other groups challenge with isolate (22). Fig (5) showing that log of antibody titer in the 6 groups, group (6) of high value in compare with other groups challenge with isolate (20)
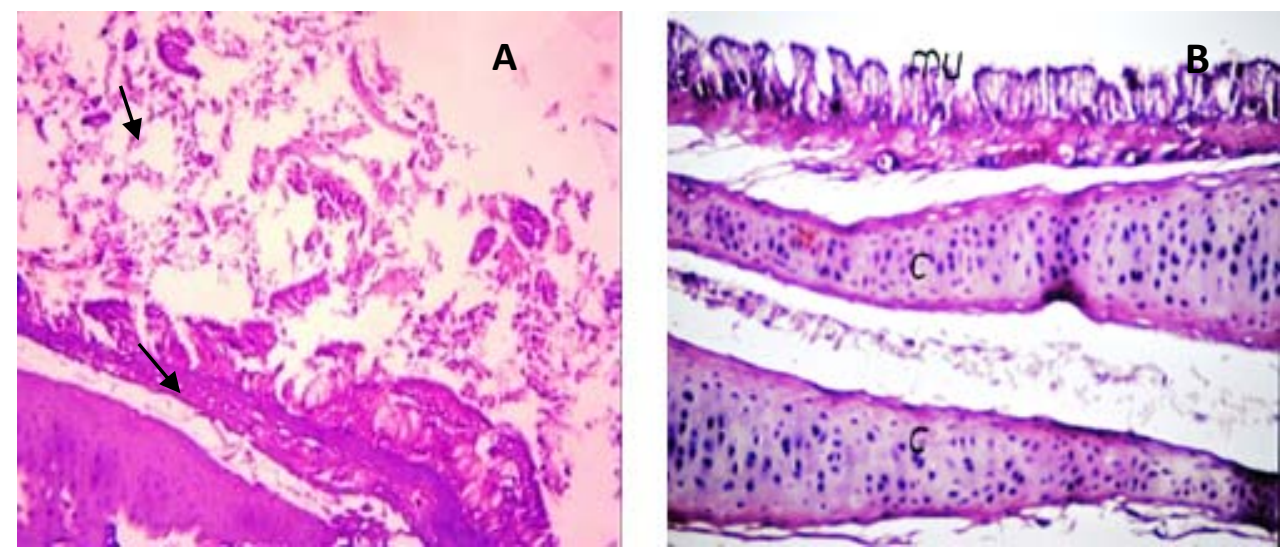
Fig( 6) : (A)Trachea of control positive group chicks infected with isolate code (20) at 26 days old showing severe desquamation of the tracheal epithelium mixed with leukocytic infiltration. H\&EX100. (B): Trachea of normal histological structure. H\&E X100
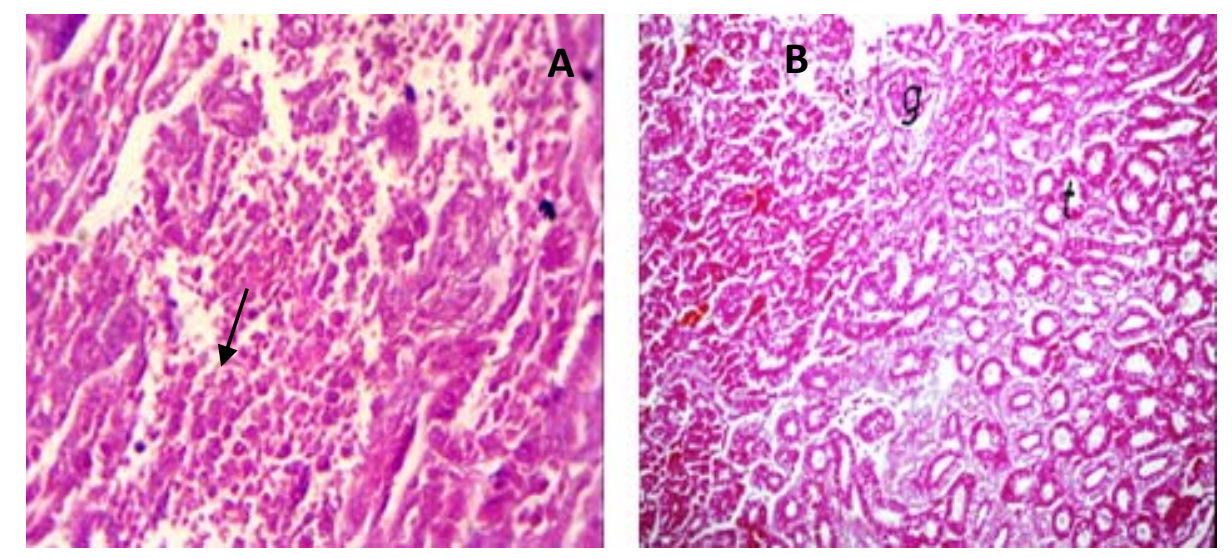

Fig (7): Kidney of control positive group chicks infected with isolate code (22) at 26 days old showing focal area of necrosis in the renal medulla H\&EX100. (B): Kidney of normal histological structure. H\&EX100.

AGP test and (RT-PCR). Also Madbouly et al., (2002) examined three field IBV strains isolated from different governorate using RT-PCR and S1 partial gene sequence. The selected sixteen samples inoculated in SPFECE, some of them showed typical IBV lesion as curling and dwarfing of the embryo and this agreed with the results reported by Cook et al., (1976). The isolated strain were confirmed to be IBV by RTPCR, IBV specific primers was applied to RNA extraction from selected sixteen isolates, then carried out RT-PCR . Positive results revealed showed band through gel electrophoresis. Our results revealed that positive amplified band showed almost at 600 base pair size product was appeared. Out of sixteen isolates only seven samples was positive IBV. This result indicated that these IBV primers are universally applicable on IBV strains and therefore provided a useful tool for detection and identification of IBV isolates, and the results come in accordance with Andreasen et al., (1991), Zwaagstraet al., (1992); Alvarado et al., (2006) and Callison et al., (2006) who showed that this technique is being used increasingly, usually after multiplication of IBV in vitro to improve sensitivity. The IBV RNA is reverse transcribed to c-DNA by the enzyme RT. Subsequently, the cDNA is amplified many times using the PCR technique. After amplification, the PCR product is to be identified as originating from IBV by another technique such as sequencing.

For identification of genotyping of these isolates, we carried out genotyping techniques including nucleotides alignment, nucleotides identity and phylogentic analysis. IBV strains have been classified based on S1 gene antigenicity into different genotypes. Recently, genotype classification based on the IBV $\mathrm{S}$ gene sequence has been adopted worldwide (Cavanagh, 2008). Similarly, our results come in agreement with Abdel-Moneim et al. (2006) who isolated an Egyptian IBV strain; Egypt $\mathrm{F} / 03$ from a tissue pool of kidney and trachea from unvaccinated broiler flock. S1 sequence analysis of the isolate revealed its close relatedness to Mass serotype. A protection study using the H120 live attenuated vaccine showed low protection rate in spite of high $\mathrm{S} 1$ sequence homology (97\%). Also El-Mahdyet al; (2010) isolated three strains of (IBV) with sever nephropathological characteristics from Mansoura, Gharbia and Giza governorates. phylogenetic analysis revealed that these strains are related to the 
IS/1494/06 nephropathic IBV strain. In addition to Hassanein, (2013); isolated eight IBV strains, three isolates were found to be mostly related to $6 / 82$ classical strain by partial S1gene sequencing and the other five were mostly related to IS/1494/06 variant II strain isolated in Israel. From phylogenetic analysis and identity percentage analysis we find that our results come in disagreement with Abdel-Moneim et al., (2012) who find five avian (IBV) isolates from broiler chickens showing respiratory and renal lesions. Three out of five isolates formed a distinct phylogenetic group with the Egypt/Beni-Suef/01 variant (Var. 1). Two of the five isolates showed 89 and $84 \%$ amino acid sequence identity and 89 and $88 \%$ nucleotide sequence identity to the Egyptian variant 1 and the IS/885 strains, respectively. Moreover, Karim, (2013) carried out phylogenetic analysis for 13 isolates and other IBV from the Middle East .Eleven out of the thirteen inoculums had close relationship with the Israeli variant (IS/885) reached up to $89.9 \%$. The other two inoculums had close relationship with, $\mathrm{CR} / 88121$ and 4/91 viruses with identities $95 \%$ and $96 \%$ respectively.

In our experimental study, vaccination with different types of IB vaccine programme showed no mortality and mild conjunctivitis at $3^{\text {rd }}$ day after challenge in some birds of groups 1,2 and 4, which vaccinated with (4/91+MA5), (CR88+H120) and (MA5+4/91) respectively and clinical signs of tracheal rales and conjunctivitis mainly of first or second type with reluctant to move and in some cases presence of difficult respiration in group (7) (un vaccinated challenged group) either with isolate (20) which start at $48 \mathrm{~h}$ post infection and $72 \mathrm{~h}$ in case of isolate (22) signs in challenged group mainly of the third type as compared with birds in group (8) (-ve control group) .Vaccinated with (IB48+ IB primer), (IB primer +IB 48), IB 4/91+ MA5), (MA5+4/91), (H120+CR88) and $(\mathrm{CR} 88+\mathrm{H} 120)$ gave protection rate (100, 96.6, $93,90,86.6$ and 83.3) respectively against isolate code (20) and
$(100,93,90,83.3$ and 86.6$)$ respectively against isolate code (22). In fig (3) showed that the S1 similarity for two challenged strains code (20) and code (22) 56\% S1 similarity strain for classical vaccinal strain and $55 \%$ for variant vaccinal strain when used one dose and one type of vaccine. However, in our study we used classical with variant strains of vaccine. This results agree with Susan et al., (2012) observed that chickens vaccinated with different types of variant or classical vaccinal strain as one dose of vaccination gave protection ranged from $83 \%$ when used $\mathrm{H} 120$ and $100 \%$ in IB primer against isolated variant (IB-IS/885) that isolated from Egypt at may 2012. In relation to body weight, our results come in agreement with susan et al., (2012) who found that the body weight affected at 7 days after using (IB- IS/885) as challenge strain for different types of live attenuated vaccinated groups. Sasipreeyajan et al., (2012) reported that different vaccine programs could not prevent the effect of the disease on body weight gain. Birds in group (6) (IB48+ primer) and group (3) (IB primer+IB48) had a high antibody level than other groups when comparison with unvaccinated negative control (156). Our finding indicated that when used vaccinal program as classical IB48 and variant IB primer give high antibody titer than when used MA5+4/91 or H120+CR88 under condition of our experiment. This results come in agreement with (Pensaert and Lambrechts 1994), (Alvarado et al , 2003), (Hamel et al, 2006), (Martin et al, 2007) ,(Salma et al, 2010) and (susanet al, 2011) they compare ELISA antibody level in birds vaccinated with commercial classical or variant IB vaccine also vaccine prepared from local isolated variant IB strain related to 4/91 which gave high level of antibody than commercial classical vaccine.

Histopathological findings was one of the important aspects in our experimental work to localize the pathological changes in affected organs trachea and kidney associated with two local variant isolated strains (20), (22) which was found to be 
related to variant (IS/1494/06). In the present study, the histopathological findings of trachea revealed presence of eosinophilic debris in the lumen mixed with desquamated epithelial cells and mononuclear cellular aggregation. . Sometimes, presence of vacuoles in the tunica muscularis of the trachea. The lamina propria revealed mild congested blood vessels associated with hemorrhages. With respect of these results similar to that recorded by (Mahgoub et al., 2010) who find that The common findings in trachea of chicks infected at 1 day old with field isolates of IBVs were generally localized in the mucosa and lamina propria. The mucosa revealed variable degrees ranged from edema to mild or sever pronounced degeneration of the epithelial lining. In addition, the lamina propria revealed mild congested blood vessels associated with hemorrhages, and infiltration with inflammatory cells. Kidney lesions of IBVinfected chicks revealed presence of an interstitial nephritis. The virus caused degenerative changes in the renal tubules. Focal area of necrosis in the renal medulla, severe congestion of the renal blood vessels with mild inter tubular hemorrhage. With respect of these results similar to that recorded by (Mahgoub et al., 2010) who find kidney lesions of IBV-infected chicks were of an interstitial nephritis. The virus caused granular degeneration, vaculation and desquamation of the tubular lesions in tubules was most prminent in the medulla.

\section{CONCLUSION}

The used vaccines failed for saving sufficient protection for chicken farms as we isolated variant field strains related to israline strains (IS/1494/06) and (IB isolate-variant $-2 \mathrm{~S} 1$ ) that made more economic problems and mortalities especially in broiler farms. We need vaccination with different vaccinal program as combination between classical and variant IB vaccine in $1^{\text {st }}$ or $2^{\text {nd }}$ dose of vaccination. This confirms that under field conditions we use vaccination programs based on our results to reduce the economic losses caused by variant IB infection viruses in Egypt. It is critical to complete genetic characterization of circulating IBV viruses to study the genetic relatedness among viruses and vaccine strains. This will guide us for best vaccines selection and improve our effort to control the disease.

\section{REFERENCES}

Abdel-Moneim, A.S., Madbouly, H.M., Gelb, J Jr. Ladman, S. 2002. Isolation and identification of Egypt/ Beni-Suef/01 a novel infectious bronchitis-virus genotype. Vet .Med .J. Giza 50(4):10651078.

Abdel-Moneium, A.S., El-Kady, M.F., Ladman, B.S., Gelb, J .Jr. 2006. S1 gene sequence analysis of a nephropathogenic strain of avian infectious bronchitis virus in Egypt. Virology Journal 3:78.

Abdel-Moneim, A.S., Afifi, M.A., El-Kady, M.F. 2012. Emergence of a novel genotype of avian infectious bronchitis virus in Egypt. Archives of virology, DOI: 10.1007/s00705-012-1445-1.

Alvarado, I.R., Villegas, P., El-Attrache, J., Brown ,T.P. 2003.Evaluation of the protection conferred by commercial vaccines against the California 99 isolate of infectious bronchitis virus .Avian Dis . 47:1298-1304.

Alvarado, I.R., Villegas, P., El-Attrache, J., Jackwood, M.W. 2006. Detection of Massachusetts and Arkansas serotypes of infectious bronchitis virus in broilers. Avian Diseases, 50:292-297.

Amin, Afaf, Mostageer, M. 1977. A preliminary report on an avian infectious bronchitis virus strain associated with nephritisnepnrosis Syndrome in chickens. J .Egypt. Vet.Med.Ass., 37 (2): 71-79.

Andreasen, J.R., Jackwood, M.R., Hilt, D.A. 1991.polymerase chain reaction amplification of the genome of infectious bronchitis virus. Avian Diseases, 35,216220.

Avellaneda, G.E., Villegas, P., Jackwood, M.W., King, D.J. 1994. In vivo evaluation of the pathogenicity of field isolates of infectious 
Bancroft, J.D., Stevens, A. 1977. Theory and practices of histologic techniques 2nd Eds. Churchill, Living Stone Edingburgh, London

Callison, S.A., D.A. Hilt, T.O. Boynton, B.F. Sample, R. Robison, D.E. Swayne, , M.W. Jackwood. 2006. Development and evaluation of a real-time Taqman RT-PCR assay for the detection of infectious bronchitis virus from infected chickens. $J$ Virol Methods. 138:60-65.

Cavanagh, D. 1983. Coronavirus IBV: structural characterization of the spike protein. J. Gen. Virol. 64:2577-2583

Cavanagh, D., Davis P. J., 1986. Coronavirus IBV: removal of spike glycopolypeptide S1 by urea abolishes infectivity and haemagglutination but not attachment to cells. J. Gen. Virol. 67, 1443- 1448.

Cavanagh, D., Davis, P.J., Mockelt, A.P. 1988. Amino acids with hypervariable region 1 of avian coronavirus IBV (Massachusetts serotype) spike glycoprotein are associated with neutralization epitops. Virus Research, 11, 141-150.

Cavanagh, D. and Naqi, S.A. 1997. Infectious bronchitis. In B.W. Calnek, H.J. Barnes, C.W. Bearol, L.R. Mc Daugald, and Y.M. Saif (eds). Disease of Poultry 10th Ed. Lawa University Press: Ames, IA, 511526.

Cavanagh, D. 2003. Severe acute respiratory syndrome vaccine development: experiences of vaccination against avian infectious bronchitis coronavirus. Avian Pathol. 32:567-582.

Cavanagh, D., Gelb .J Jr. 2008. Diseases of poultry .Y.M.Saif, ed. Blackwell publishing, Iowa. Pp 117-135.

Cook, J.K., Darbyshire, J.H, Peters, R.W. 1976. The use of chicken tracheal organ culture for the isolation and assay of avian infectious bronchitis .Arch.Viral.50,109118.

Cook, J.K.A., Orbell, S.J., Woods, M.A. , Huggins, M.B. 1999. Breadth of protection of the respiratory tract provided by different live-attenuated infectious bronchitis vaccines against challenge with infectious bronchitis viruses of heterologous serotypes. Avian Pathology, 28, 477-485.

El-Mahdy, S.S., El-Hady, M.M. , Soliman, Y.A. 2010. Isolation and Characterization of Nephropathogenic Strain of Infectious
Bronchitis Virus in EGYPT.Journal of American Science; 6(9):669-675.

Gelb, J., Jr. 1989. Infectious bronchitis. In: purchase et al (Eds). A Laboratory Manual for the Isolation and Identification of Avian Pathogens. 3rd. Ed.AAAP, 124-127.

Gelb, J., Weisman,Y., Ladman,B.S, Meir, R. 2005.Gene characteristics and efficacy of vaccination against infectious and Israel (1996 to 2000) Avian pathology, $34,194-$ 203.

Gorgyo,M.., Umemura , T. and Itakura, C. 1984. Concurrence of nephrosis-nephritis due to infectious Bronchitis virus and infectious bursal disease in Broiler chickens Avian Pathology, 13, 191-200, 1984.

Hamel, K.R., Burgess, S.C., Pevzner, I.Y, Erf, G.F. 2006. Maternal antibody transfer from dam to their egg yolks, egg whites, and chicks in meat line of chickens. Poultry.Science.85:1364-1372.

Hassanein, 2013. Screening on some viral etiologies agent causing kidney affection on broiler chickens. M.V.Sc. Thesis, Fac. Vet. Med., Cairo Univ., Giza, Egypt.

Ignjatovic, J., Sapats, S. 2000. Avian infectious bronchitis virus. Rev. Sci. Off. Int. Epiz. 19: 493-508.

Karim, 2013. Molecular epidemiology of infectious bronchitis in Egypt 2012. M.V.Sc. Thesis, Fac. Vet.Med., Cario Univ., Giza, Egypt.

Koch, G., Hartog, L., Kant, A., Van Roozelaar, D.J. 1990. Antigenic domains on the peplomer protein of avian infectious bronchitis virus:

Kusters, J.G., Niesters, G.M., Bleumink-Pluym, N.M., Davelaar, F.G.; Herzinek, M.C. , Van der Zeijst, B.A. 1987. Molecular epidemiology of infectious bronchitis virus in the Netherlands. J. Gen. Virol. 68:343352.

Madbouly, H.M.., Abdel-Moneim, A.S., Gelb, J.Jr., Landman, B.S. 2002. Molecular characterization of three Egyptian isolates of infectious bronchitis virus. Vet.Med. J.Giza. 50(4):10533-1064.

Mahgoub, K.M., Bassiouni. A.A., Manal A. Afify, Rabie, S., Nagwa 2010. The Prevalence of Infectious Bronchitis (IB) Outbreaks in Some Chicken Farms. III. Cross Protection of Vaccinated Chickens versus Field IB Virus. Journal of American Science; 6(9):94-108. 
Martin, M.P., Wakenell, P., Woolcock, P., OConor B. 2007.Evaluation of the effectiveness of two infectious bronchitis virus vaccine programs for preventing disease caused by California IBV field isolate. Avian Dis. 51: 554-589.

Momayez, R., Pourbakhsh, S.A., Khodashenas, M., Banani, M. 2002. Isolation and Identification of Infectious Bronchitis Virus from Commercial Chickens Arch. Razi Ins. (53)

Pensaert, M., Lambrechts, C. 1994. Vaccination of chickens against a Belgian nephropathogenic strain of infectious bronchitis virus B1648 using attenuated homologus strains. Avian pathology 23:631-641.

Reed, L.J., Muench, H. 1938. A simple method for estimating fifty percent endpoint. Am. J. Hyg., 27:493-496.

Salma. S.S., Eman, A. Hasan., Hanan, E. Mohammed., Eman, S. Ahmed., Nadisa, Ebrahim, Susan, S. El-Mahdy .2010. Trail for preparation and evaluation of combined vaccine against ND, IB and M.gallisepticum diseases in chickens. BS.Vet. Med.J. $6^{\text {th }}$ Sce . Conf. 20 (1):263267.

Sasipreeyajan. Jiroj, Tawatchai, Pohuang \& Nida sirikokul 2012. Efficacy of different vaccination bronchitis virus. Thai $\mathrm{J}$ Vet Med. 42(1):73-79.

SPSS .2004. Statistical package for social sciences. Release 16.01 version .SPSS Inc.

Susan, S. El-Mahdy., Y.A., Soliman, M.M. ElHady .2011. Preparation and evaluation of Master Seed for infectious bronchitis vaccine from local variant isolate. Nature and science ; 9 (10) 145-151.
Susan, S .El-Mahdy, Ekram. Salama, Amal. Ahmed .2012. Efficacy of some living classical and variant infectious bronchitis vaccines against local variant isolated from Egypt. Nature and Science10 (12) 292299.

Thompson, G., Mohammed, H.; Buaman, B., Nagi, S. 1997. Systemic and local antibody responses to infectious bronchitis virus in chickens inoculated with infectious bursal disease virus and control chickens. Avian Dis. 41:519-527.

Villegas, P., Purchase, G.H. 1990. Preparation of chicken embryo kidney cell cultures (CEKC). In: Laboratory manual for the isolation and

Wang, C.H., Huang, Y.C. 2000. Relationship between serotypes and genotypes based on the hypervariable region of the S1 gene of infectious

Wang, C.H., Tsai, C.T. 1996. Genetic grouping for the isolates of avian infectious bronchtis viruses in Taiwan. Arch. Virol., 141: 1677-1688.

Wang, H.N., Wu, Q.Z., Huang, Y. 1997. Isolation and identification of infectious bronchitis virus from chickens in Sichuan, China. Avian. Dis., 41:279-282.

Yu, L., Wang, Z., Jiang, Y., Low, S., Kwang, J. 2001. Molecular epidemiology of infectious bronchitis virus isolates from China and southeast Asia. Avian Diseases, 45: 201-209.

Zwaagstra, K.A., van der Zeijst, B.A.M., Kusters, J.G. 1992. Rapid detection and identification of avian infectious bronchitis virus. Journal of Clinical Microbiology, 30:79-84. 